\title{
Has the search for a marker of activated fibroblasts finally come to an end?
}

Citation for published version (APA):

Blankesteijn, W. M. (2015). Has the search for a marker of activated fibroblasts finally come to an end? Journal of Molecular and Cellular Cardiology, 88, 120-123. https://doi.org/10.1016/j.yjmcc.2015.10.005

Document status and date:

Published: 01/11/2015

DOI:

10.1016/j.yjmcc.2015.10.005

Document Version:

Publisher's PDF, also known as Version of record

Document license:

Taverne

Please check the document version of this publication:

- A submitted manuscript is the version of the article upon submission and before peer-review. There can be important differences between the submitted version and the official published version of record.

People interested in the research are advised to contact the author for the final version of the publication, or visit the DOI to the publisher's website.

- The final author version and the galley proof are versions of the publication after peer review.

- The final published version features the final layout of the paper including the volume, issue and page numbers.

Link to publication

\footnotetext{
General rights rights.

- You may freely distribute the URL identifying the publication in the public portal. please follow below link for the End User Agreement:

www.umlib.nl/taverne-license

Take down policy

If you believe that this document breaches copyright please contact us at:

repository@maastrichtuniversity.nl

providing details and we will investigate your claim.
}

Copyright and moral rights for the publications made accessible in the public portal are retained by the authors and/or other copyright owners and it is a condition of accessing publications that users recognise and abide by the legal requirements associated with these

- Users may download and print one copy of any publication from the public portal for the purpose of private study or research.

- You may not further distribute the material or use it for any profit-making activity or commercial gain

If the publication is distributed under the terms of Article $25 \mathrm{fa}$ of the Dutch Copyright Act, indicated by the "Taverne" license above, 
Editorial

\section{Has the search for a marker of activated fibroblasts finally come to an end?}

Keywords:

Cardiac fibrosis

Proto-myofibroblast

Myofibroblast

Marker

Fibroblast activating protein

In a recent issue of the Journal of Molecular and Cellular Cardiology, Tillmanns et al. [1] describe the identification of activated fibroblasts by their expression of Fibroblast Activation Protein alpha (FAP). They observed FAP-positive fibroblasts in infarcted rat and human hearts and studied the co-expression of FAP with different markers for (myo)fibroblasts. The authors also studied the signaling pathway leading to FAP expression and the role of FAP in cell proliferation, migration and gelatin degradation. From these combined experiments, the authors conclude that FAP expression is restricted to fibroblasts in an activated state, and that FAP is actively involved in the remodeling process.

Fibroblasts play an essential role in cardiac physiology. First of all, they are responsible for the production of the network of extracellular matrix (ECM) that surrounds the cardiomyocytes, and is involved in the transfer of their contractile force to the ventricular cavity. During cardiac development, most of the cardiac fibroblasts are derived from the epicardium by a process called epithelial-to-mesenchymal transfer (EMT) [2]. These cells migrate into the myocardium where they are localized between the cardiomyocytes and form a pool of resident cardiac fibroblasts. Some fibroblasts are derived from the endocardial cushions, with the cardiac valves and the atrio-ventricular septum as their main destination $[3,4]$. Under normal circumstances, these resident cardiac fibroblasts are in a quiescent state, characterized by low levels of proliferation and ECM synthesis [5]. However, when the heart responds to a challenge this is associated with an activation of fibroblasts. These challenges can be as diverse as ischemia, pressure or volume overload or an inflammatory response to pathogens. Despite their rather diverse nature, all of these challenges lead to an increased deposition of ECM, a process referred to as cardiac fibrosis. Excessive ECM deposition is generally considered to be disadvantageous for the pump function of the heart, as this can lead to stiffening of the myocardium and perturbations of the electrical conductance. These events are generally indicated by the term 'adverse cardiac remodeling' [6].

The activation of cardiac fibroblasts in the remodeling heart coincides with a change in the phenotype of these cells. This differentiation was first described by Gabbiani et al. who introduced the term 'modified fibroblast' to describe this phenotypical change [7]. These differentiated fibroblasts, nowadays referred to as myofibroblasts, combine an augmented synthesis of ECM with the generation of a sustained contractile force. These characteristics make myofibroblasts instrumental in the wound contraction that can be observed in the injured skin, before the scar tissue develops. A similar role can be anticipated for myofibroblasts in the infarct area, where replacement of the necrotic cardiomyocytes with a compact scar is beneficial for cardiac function [8].

The factors controlling the myofibroblast differentiation are extensively studied. Upon exposure to mechanical tension and factors such as platelet-derived growth factor (PDGF) and the ED-A splice variant of fibronectin, a transient phenotype called proto-myofibroblast is induced [9]. These proto-myofibroblasts contain stress fibers and show an increased expression of collagens and ED-A fibronectin. Exposure of the proto-myofibroblasts to other growth factors such as Transforming Growth Factor-beta (TGF $\beta$ ), connective tissue growth factor (CTGF/ CCN2) and/or Angiotensin II (AngII) induces the conversion to a full myofibroblast phenotype characterized by the expression of alpha smooth muscle actin ( $\alpha$ SMA) and a further increase in production and cross linking of collagen fibers [10]. The expression of the smooth muscle actin isoforms allows the myofibroblasts to exert a sustained contractile force to their environment [11].

There is increasing evidence that myofibroblasts in the remodeling heart are not solely a differentiated form of resident cardiac fibroblasts, but that multiple cellular sources can contribute. In this context, epicardial epithelial cells, endothelial cells, mesenchymal stem cells, bone marrowderived fibrocytes and pericytes have been shown to contribute to the myofibroblast pool in the remodeling heart [12]. This large variety in origins of the myofibroblasts in the remodeling heart helps to explain why it is so difficult to find specific molecular markers for this cell type. The markers that have been used the most frequently in this context will be described briefly.

\section{a-Smooth muscle actin}

As indicated above, $\alpha$ SMA is part of the contractile machinery that allows the myofibroblast to develop a contractile force. $\alpha$ SMA is the most widely accepted molecular marker to identify myofibroblasts because $\alpha S M A$ expression is considered to be a key feature of the differentiated myofibroblast, indifferent of its origin. However, there are several drawbacks in the use of this marker, as it is not specific for myofibroblasts but also expressed in smooth muscle cells of e.g. arteries [13].

\section{Discoid domain receptor 2 (DDR2)}

DDR2 is a receptor tyrosine kinase that uses triple helix collagen I and III as a ligand. Activation of DDR2 results in the augmented transcription 
of multiple genes including many matrix metalloproteinases. DDR2 is expressed in mesenchymal cells throughout the body, but in the heart its expression is confined to fibroblasts. Mice lacking the DDR2 gene are small and have an abnormal cardiac structure and function [14]. At present it is not clear whether DDR2 expression can still be observed in (proto)myofibroblasts in the heart [15].

\section{Extra domain-A (ED-A) fibronectin}

ED-A fibronectin is a variant of fibronectin that is the result of alternative splicing of the extra domain-A. The differentiation towards the myofibroblast phenotype requires a combination of mechanical stress, TGF $\beta$ and ED-A fibronectin, and the ED-A fibronectin can be produced by (myo)fibroblasts [16]. Because the latter molecule will mainly remain localized in the direct vicinity of the producing cells, ED-A fibronectin has been proposed as a marker for myofibroblasts [17].

\section{Fibroblast-specific protein 1 (FSP1)}

As the name implies, FSP1 was originally identified in fibroblasts by differential and subtractive hybridization. It was described as a fibroblast-specific protein with little or no expression in a wide range of non-fibroblast cells including proximal tubular cells, mesangial cells, lymphocytes and endothelial cells. FSP1, which is a member of the S-100 family, functions as a cytoplasmic calcium binding protein that can interact with the cytoskeleton. Overexpression of FSP1 in tubular epithelial cells induced the conversion of these cells to a fibroblastlike morphology [18]. Recently, however, the specificity of FSP1 for fibroblasts has been questioned. Using models of ischemia/reperfusion and pressure overload, Kong et al. demonstrated FSP1 expression in hematopoietic cells, endothelial cells and vascular smooth muscle cells. From these results the authors concluded that FSP1 is not a fibroblastspecific marker in cardiac remodeling and fibrosis. The authors recommend the use of periostin rather than FSP1 as a marker of activated fibroblasts in the remodeling myocardium [19]. However, as it is becoming increasingly clear that bone marrow-derived fibrocytes, pericardial epithelial cells, mesenchymal stem cells and endothelial cells all can contribute to the pool of activated fibroblasts in the remodeling heart [12], an alternative explanation for their findings may be that FSP1 starts to be expressed somewhere during the transition of these diverse precursors towards the myofibroblast phenotype.

\section{Periostin}

Periostin was originally identified as a factor secreted by osteoblasts. The name is derived from its high levels of expression in periosteum and periodontal ligaments. Periostin expression is observed in connective tissue exposed to mechanical stress, such as periosteum and cardiac valves [20]. In the embryonic heart, periostin is strongly expressed in the mesenchymal cells derived from the epicardium via epithelial-tomesenchymal transition (EMT), but is not expressed in the developing cardiomyocytes. Periostin acts as a matricellular protein in that the protein is attached to the ECM but, rather than having a structural role, can exert an effect on cellular phenotypes. The protein is mostly excreted and can interact with ECM components such as collagen I, but it can also serve as a ligand for certain integrins [21]. Periostin expression is increased in the infarct area, starting at 4 days post-MI, and localized in the (myo)fibroblasts. Loss-of-function experiments have shown that periostin-deficient mice had a higher incidence of infarct rupture, fewer myofibroblasts and reduced deposition of collagen fibrils in their infarcts compared to wildtypes. Periostin expression is also increased in models of pressure overload-induced hypertrophy and fibrosis [22].

\section{Prolyl-4-hydroxylase}

Prolyl-4-hydroxylase ( $\mathrm{P} 4 \mathrm{H})$ is an enzyme involved in the posttranslational processing of alpha chains of pro-collagen. The hydroxylation of proline residues by $\mathrm{P} 4 \mathrm{H}$ facilitates the formation of the triple helix of mature collagen. This enzyme was originally found to be upregulated in a rat model of myocardial infarction (MI) [23]. P4H expression is high in the fibroblast subtypes that produce ECM at a high level, including activated fibroblasts and myofibroblasts. Because of its role in the maturation of collagen, $\mathrm{P} 4 \mathrm{H}$ can serve as a marker for activated fibroblasts and myofibroblasts [24], but this marker can be expressed by fibrocytes and macrophages as well [25].

\section{Thy-1}

Thy-1 is a glycosylphosphatidylinositol (GPI)-anchored protein with a molecular weight of $25-37 \mathrm{kDa}$. It is involved in focal adhesion, stress fiber formation and multiple signaling pathways [26]. Thy- 1 can be expressed in multiple cell types, including fibroblasts, endothelial cells, neurons and hematopoietic cells. Although Thy-1 expression has been reported to be heterogeneous in fibroblasts in different organs, the fibroblast population of the rat heart was reported to be entirely Thy $-1^{+}$. Interestingly, Thy-1 expression was found to be relatively stable in throughout the differentiation states of fibroblasts, and can also be observed in myofibroblasts in the hearts of DOCA-salt hypertensive rats [27].

\section{Vimentin}

Vimentin is an intermediate filament protein that is expressed in cells from mesenchymal origin such as fibroblasts, smooth muscle cells and bone. It can be used in combination with desmin to identify fibroblasts, which should be vimentin ${ }^{+} /$desmin $^{-}$as desmin is present in muscle cells. Due to its characteristics, vimentin expression is likely to be present in the entire spectrum of (myo)fibroblasts, as shown in the postnatal rat heart [28].

In their manuscript, Tillmanns et al. propose FAP as a marker for activated fibroblasts. Unlike some of the (myo)fibroblast markers described above, FAP is not involved in matrix production but is an enzyme with both dipeptidyl peptidase and endopeptidase activity. FAP is able to cleave collagen I, but only after destruction of the triple helix by e.g. MMP1. The enzyme is expressed at low levels in adult tissue, but overexpression occurs in conditions such as wound healing, arthritis, atherosclerosis and tumor metastasis. Interestingly, the proteolytic activity of FAP is not restricted to ECM proteins, as this enzyme has also been reported to cleave peptidergic mediators such as Neuropeptide Y, Brain Natriuretic Protein and Substance P [29].

The expression of FAP was studied in infarcted rat hearts at 3, 7 and 28 days post-MI as well as sham-operated hearts. Expression of FAP was low in sham hearts but was present in the border zone around the infarct at day 3 and 7 days post-MI and inside the infarct area at 28 days post-MI. Co-localization experiments of FAP and P4H showed that part of the P4H-positive cells were also FAP-positive, identifying them as fibroblasts that actively synthesize collagen. On the other hand, part of the FAP-positive cells in the infarct area co-expressed $\alpha$ SMA, identifying them as myofibroblasts. Most of the FAP-positive cells expressed vimentin, confirming their mesenchymal nature. FAP-expression was rare in non-fibroblast cells such as inflammatory cells, endothelial cells or vascular smooth muscle cells. The authors conclude from these results that FAP identifies predominantly proto-myofibroblasts and a minority of the myofibroblasts in the infarcted rat heart [1].

FAP expression was subsequently investigated in infarcted human hearts. The authors could confirm that FAP is expressed in cells with a spindle-shaped, fibroblast-like morphology. Part of the $\mathrm{FAP}^{+}$cells also expressed Thy- 1 . As indicated above, Thy- 1 is uniformly expressed by the fibroblasts in the rat heart but in other organs the fibroblasts show a heterogeneous Thy- 1 expression which may be a reflection of their origin 


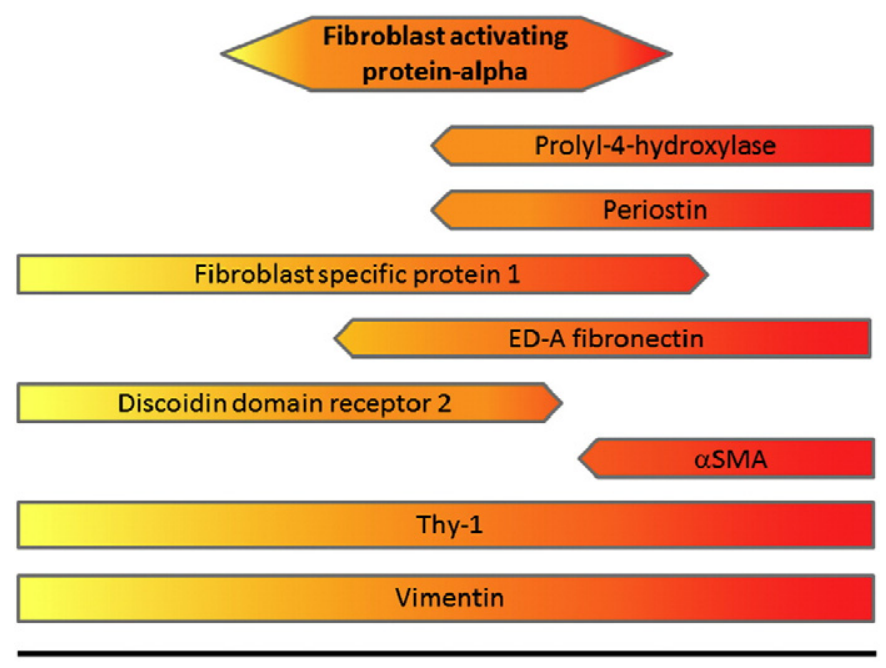

\section{Fibroblast Proto-myofibroblast Myofibroblast}

Fig. 1. Schematic representation of the expression pattern of molecular markers that are frequently used in the histological identification of fibroblasts, proto-myofibroblasts and myofibroblasts. For the literature references from which these expression patterns were derived, please refer to the description of the individual markers in the main text. $\alpha S M A$ : alpha smooth muscle actin.

[27]. Only a small fraction of the FAP-expressing cells were also positive for $\alpha \mathrm{SMA}$, underscoring the findings from the rat study that FAP expression is the most strongly associated with the proto-myofibroblast phenotype [1].

The signaling pathway that induces FAP expression was further investigated in vitro. The authors report that treatment of cultured adult cardiac fibroblasts with TGFB induces the expression of FAP. Treatment with either SB431542 or siRNAs indicated that this activation of FAP expression results from activation of the canonical SMAD pathway. Zymography experiments revealed that treatment of the cardiac fibroblasts with TGFß also increased the gelatinolytic activity of a $170 \mathrm{kDa}$ band which corresponds to the dimerized, enzymatically active form of FAP. Moreover, siRNA-mediated inhibition of FAP expression impaired the migratory capacity of the fibroblasts in a transwell migration assay. From these results, it can be deduced that FAP helps the protomyofibroblasts during their migration from the border zone into the infarct area [1].

From their data, Tillmanns et al. conclude that FAP is expressed by activated, collagen-synthesizing fibroblasts, but not by inactive fibroblasts or fully differentiated myofibroblasts and non-fibroblast cells in the infarct. As illustrated in Fig. 1, this would provide a unique expression pattern for this marker, as the markers that are currently used (with the exception of vimentin and Thy-1) are either expressed at the inactive fibroblast-side or the fully differentiated myofibroblast-side of the spectrum. Addition of FAP to the panel of markers therefore is likely to help in the accurate molecular description of the (myo)fibroblast phenotype in the remodeling heart. However, some questions will need to be answered to fully understand the position of FAP in this respect. It is increasingly clear that (proto-)myofibroblasts in the remodeling heart can be derived from multiple sources, including epithelial and endothelial cells, mesenchymal stem cells and circulating fibrocytes. Analysis of the co-expression of FAP with markers identifying the origin of the proto-myofibroblasts will be required to scrutinize whether FAP is a universal marker for this cell type or whether its expression is restricted to proto-myofibroblasts from distinct sources. Despite these unresolved questions, FAP has the potential to be a valuable tool in the study of the fibrotic response that takes place in the remodeling heart.

\section{Disclosures}

None.

\section{References}

[1] J. Tillmanns, D. Hoffmann, Y. Habbaba, J.D. Schmitto, D. Sedding, D. Fraccarollo, et al., Fibroblast activation protein alpha expression identifies activated fibroblasts after myocardial infarction, J. Mol. Cell. Cardiol. 87 (2015) 194-203.

[2] J.C. Kovacic, N. Mercader, M. Torres, M. Boehm, V. Fuster, Epithelial-to-mesenchymal and endothelial-to-mesenchymal transition: from cardiovascular development to disease, Circulation 125 (2012) 1795-1808.

[3] A.C. Gittenberger-de Groot, M.P. Vrancken Peeters, M.M. Mentink, R.G. Gourdie, R.E Poelmann, Epicardium-derived cells contribute a novel population to the myocardial wall and the atrioventricular cushions, Circ. Res. 82 (1998) 1043-1052.

[4] A. Deb, E. Ubil, Cardiac fibroblast in development and wound healing, J. Mol. Cell. Cardiol. 70 (2014) 47-55.

[5] P. Kong, P. Christia, N.G. Frangogiannis, The pathogenesis of cardiac fibrosis, Cell Mol. Life Sci. 71 (2014) 549-574.

[6] K.T. Weber, Y. Sun, S.K. Bhattacharya, R.A. Ahokas, I.C. Gerling, Myofibroblast-mediated mechanisms of pathological remodelling of the heart, Nat. Rev. Cardiol. 10 (2013) $15-26$.

[7] G. Gabbiani, G.B. Ryan, Presence of modified fibroblasts in granulation tissue and their possible role in wound contraction, Experientia 27 (1971) 549-550.

[8] E.P. Daskalopoulos, K.C. Hermans, W.M. Blankesteijn, Cardiac (myo)fibroblast: novel strategies for its targeting following myocardial infarction, Curr. Pharm. Des. (2013).

[9] J.J. Tomasek, G. Gabbiani, B. Hinz, C. Chaponnier, R.A. Brown, Myofibroblasts and mechano-regulation of connective tissue remodelling, Nat. Rev. Mol. Cell Biol. 3 (2002) 349-363

[10] A. Leask, Getting to the heart of the matter: new insights into cardiac fibrosis, Circ. Res. 116 (2015) 1269-1276.

[11] S.W. van den Borne, J. Diez, W.M. Blankesteijn, J. Verjans, L. Hofstra, J. Narula, Myocardial remodeling after infarction: the role of myofibroblasts, Nat. Rev. Cardiol. 7 (2010) 30-37.

[12] E.M. Zeisberg, R. Kalluri, Origins of cardiac fibroblasts, Circ. Res. 107 (2010) 1304-1312.

[13] B. Hinz, S.H. Phan, V.J. Thannickal, M. Prunotto, A. Desmouliere, J. Varga, et al., Recent developments in myofibroblast biology: paradigms for connective tissue remodeling, J. Pathol. 180 (2012) 1340-1355.

[14] R.T. Cowling, S.J. Yeo, I.J. Kim, J.I. Park, Y. Gu, N.D. Dalton, et al., Discoidin domain receptor 2 germline gene deletion leads to altered heart structure and function in the mouse, J. Physiol. Heart Circ. Physiol. 307 (2014) H773-H781.

[15] E.C. Goldsmith, A.D. Bradshaw, M.R. Zile, F.G. Spinale, Myocardial fibroblast-matrix interactions and potential therapeutic targets, J. Mol. Cell. Cardiol. 70 (2014) 92-99.

[16] E.P. Daskalopoulos, K.C. Hermans, W.M. Blankesteijn, Cardiac (myo)fibroblast: nove strategies for its targeting following myocardial infarction, Curr. Pharm. Des. 20 (2014) 1987-2002.

[17] M.A. Ngo, A. Muller, Y. Li, S. Neumann, G. Tian, I.M. Dixon, et al., Human mesenchymal stem cells express a myofibroblastic phenotype in vitro: comparison to human cardiac myofibroblasts, Mol. Cell. Biochem. 392 (2014) 187-204.

[18] F. Strutz, H. Okada, C.W. Lo, T. Danoff, R.L. Carone, J.E. Tomaszewski, et al., Identification and characterization of a fibroblast marker: FSP1, J. Cell Biol. 130 (1995) 393-405.

[19] P. Kong, P. Christia, A. Saxena, Y. Su, N.G. Frangogiannis, Lack of specificity of fibroblast-specific protein 1 in cardiac remodeling and fibrosis, J. Physiol. Heart Circ. Physiol. 305 (2013) H1363-H1372.

[20] K. Horiuchi, N. Amizuka, S. Takeshita, H. Takamatsu, M. Katsuura, H. Ozawa, et al. Identification and characterization of a novel protein, periostin, with restricted expression to periosteum and periodontal ligament and increased expression by transforming growth factor beta, J. Bone Miner. Res. 14 (1999) 1239-1249.

[21] P. Snider, K.N. Standley, J. Wang, M. Azhar, T. Doetschman, S.J. Conway, Origin of cardiac fibroblasts and the role of periostin, Circ. Res. 105 (2009) 934-947.

[22] N.G. Frangogiannis, Matricellular proteins in cardiac adaptation and disease, Physiol. Rev. 92 (2012) 635-688.

[23] H. Ju, S. Zhao, D.S. Jassal, I.M. Dixon, Effect of AT1 receptor blockade on cardiac collagen remodeling after myocardial infarction, Cardiovasc. Res. 35 (1997) 223-232.

[24] T. Moore-Morris, N. Guimaraes-Camboa, I. Banerjee, A.C. Zambon, T. Kisseleva, A Velayoudon, et al., Resident fibroblast lineages mediate pressure overload-induced cardiac fibrosis, J. Clin. Invest. 124 (2014) 2921-2934.

[25] D. Pilling, T. Fan, D. Huang, B. Kaul, R.H. Gomer, Identification of markers that distinguish monocyte-derived fibrocytes from monocytes, macrophages, and fibroblasts, PLoS ONE 4 (2009), e7475.

[26] T.A. Rege, J.S. Hagood, Thy-1, a versatile modulator of signaling affecting cellular adhesion, proliferation, survival, and cytokine/growth factor responses, BBA 1763 (2006) 991-999.

[27] F. Hudon-David, F. Bouzeghrane, P. Couture, G. Thibault, Thy-1 expression by cardiac fibroblasts: lack of association with myofibroblast contractile markers, J. Mol. Cell. Cardiol. 42 (2007) 991-1000.

[28] J. Wang, H. Chen, A. Seth, C.A. McCulloch, Mechanical force regulation of myofibroblast differentiation in cardiac fibroblasts, J. Physiol. Heart Circ. Physiol. 285 (2003) H1871-H1881.

[29] E.J. Hamson, F.M. Keane, S. Tholen, O. Schilling, M.D. Gorrell, Understanding fibroblast activation protein (FAP): substrates, activities, expression and targeting for cancer therapy, Proteomics Clin. Appl. 8 (2014) 454-463. 
W. Matthijs Blankesteijn Dept. of Pharmacology and Toxicology, Cardiovascular Research Institute Maastricht, Maastricht University, Maastricht, The Netherlands

4 October 2015 